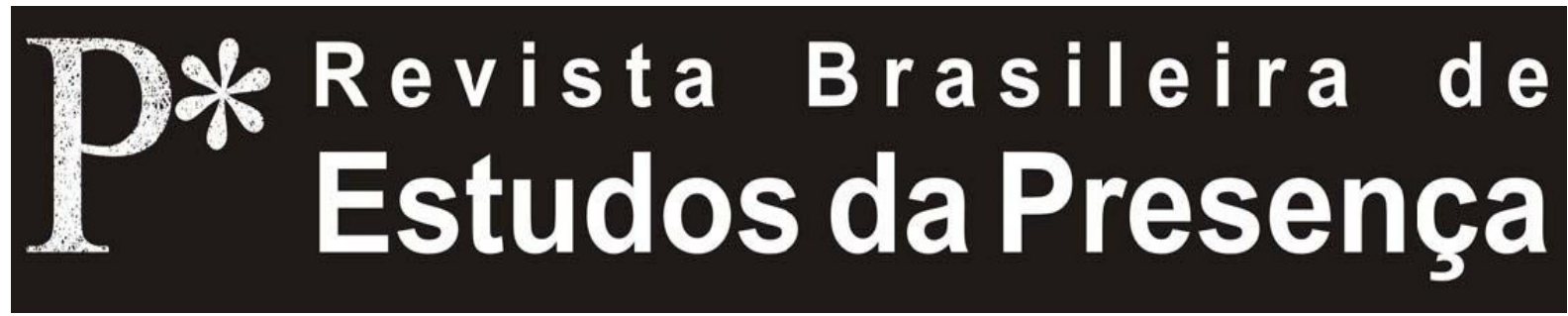

DOI - http://dx.doi.org/10.1590/2237-266039236

ISSN 2237-2660

\title{
Efectos de Presencia y Performance en el Teatro de Lola Arias
}

\author{
María Fernanda Pinta \\ Universidad de Buenos Aires - UBA, Buenos Aires, Argentina
}

RESUMEN - Efectos de Presencia y Performance en el Teatro de Lola Arias - En el actual contexto mediático y espectacular de la cultura, la expansión de la performance en prácticas diversas desafía al teatro a crear modelos alternativos de aproximación a la experiencia humana. Como respuesta, el arte teatral apelará al contacto sensible y empático de los cuerpos, a la intimidad de los vínculos afectivos, a los relatos biográficos y sus respectivas proyecciones en lo social y en la historia. El presente trabajo se propone como una indagación al teatro de la artista argentina Lola Arias en diálogo con este modelo performativo de la cultura contemporánea.

Palabras-clave: Lola Arias. Teatro Argentino. Teatro Documental. Instalación Teatral. Performance.

ABSTRACT - Effects of Presence and Performance on Lola Arias's theatre - In the current media and spectacles cultural context, the expansion of performance into different practices challenges theatre to create alternative models to approach human experience. As a response, theatre appeals to the sensitive and empathic contact of bodies with the intimacy of affective connections, with biographical stories and their respective projections in the social and historical realms. This work proposes an investigation of the theatrical work of Argentine artist Lola Arias in dialog with this performative model of contemporary culture. Keywords: Lola Arias. Argentine Theatre. Documentary Theatre. Theatrical Installation. Performance.

RÉSUMÉ - Effets de Présence et de Performance dans le Théâtre de Lola Arias Dans l'actuel contexte médiatique et spectaculaire de la culture, le développement de la performance dans diverses pratiques met le théâtre au défi de créer des modèles alternatifs d'approche dans l'expérience humaine. Pour y répondre, l'art théâtral fait appel au contact sensible et empathique des corps, à l'intimité des liens affectifs, aux récits biographiques et ses projections respectives dans le social et dans l'histoire. Ce travail se présente comme une quête dans le théâtre de l'artiste argentine Lola Arias, dans un dialogue avec ce modèle performatif de la culture contemporaine.

Mots-clés: Lola Arias. Théâtre Argentin. Théâtre Documentaire. Installation Théâtrale. Performance. 


\section{La Presencia del Teatro en la Cultura Contemporánea}

Un conjunto significativo de estudios teatrales observan que las condiciones mediáticas y espectaculares de la cultura contemporánea estarían cruzando, desde hace ya varias décadas, las prácticas y los discursos teatrales con el terreno de la vida cotidiana (De Marinis, 1997); más específicamente con el campo de las performances culturales.

Las lenguas latinas carecen de una palabra capaz de traducir performance, que no se circunscribe al teatro y que, a veces, ante la carencia de otras alternativas, se da como sinónimo de espectáculo, una palabra que más bien designa toda manifestación visual de sentido ('espectáculo del mundo'). Ahora bien, la performance cubre un ámbito inmenso que las artes del espectáculo y la etnoescenología intentan cuadrar y que impugna las fronteras existentes entre espectáculo estético y práctica cultural. [...] La noción de cultural performance, elaborada por el etnólogo Milton Singer ${ }^{1}$ en los años cincuenta, permite reunir bajo esta etiqueta prácticas culturales [juego, deporte, estética, diversión popular, teatro experimental, ritos, fiestas, ceremonias] que incluyen elementos de representación que el grupo se proporciona a sí mismo (Pavis, 1998, p. 180).

Si, por un lado, los medios de comunicación perfilan modos espectaculares de representación de la realidad; por otro, ésta última tiende a ficcionalizarse recurriendo cada vez más a las convenciones mediáticas y a los recursos dramáticos de los medios audiovisuales. Estas condiciones producen, sin embargo, cierto anhelo de acceder a una experiencia más verdadera, más auténtica de lo real; de allí que se otorgue un valor especial a las experiencias del yo, un giro subjetivo y performativo que, lejos de afirmar una subjetividad autosuficiente, se configura como tal en el proceso de su producción y en el encuentro con los otros.

Hay que agregar aquí que en esta perspectiva opera también un giro lingüistico que subraya el carácter constructivo del lenguaje (en tanto determina a la vez el pensamiento y la realidad) y la dimensión social e histórica de toda producción de sentido (abandonando los enfoques totalizadores). Es justamente este universo de significación, pero también de convencionalización y (re)producción de las conductas humanas, el espacio en el que la perspectiva performativa reflexiona tanto acerca de los modelos de comportamiento dominantes como de las prácticas alternativas a los mismos. Y aquí, la dimensión 
corporal y afectiva, pero también aquella dimensión de las imágenes, de los objetos y del lenguaje que escapan a la racionalidad moderna y sus modelos interpretativos ocupan el centro de la escena.

El teatro también dialoga con estos enfoques en torno a la performance (Pavis, 2008). La crisis de la noción de puesta en escena en tanto sistema de signos estructurados coherentemente desde el punto de vista de su lógica dramática/literaria estará de la mano del cuestionamiento de los modelos lingüísticos y semióticos tradicionales. En este contexto, la noción de performance se vuelve una herramienta teórica y práctica que permite flexibilizar los mecanismos compositivos del teatro y extender su campo de acción a los procesos creativos y la materialidad expresiva y, con ellos, a los aspectos lúdicos y sensibles de la experiencia estética.

Y es en esta dirección que los estudios de la presencia analizan las prácticas performativas:

1 - se trata de una voluntad de presencia que se manifiesta para nosotros como oposición a la hegemonía de las significaciones [...]; $2-$ a pesar de la intervención de las significaciones saboreamos los momentos de presencia que son siempre efímeros [...]; 3 - presencia y significado son apenas efectos de la experiencia vivida y encuentran en las prácticas performativas la oscilación necesaria para servir como ejemplos de modos de apropiación del mundo (Icle, 2012, p. 193).

Respecto de la experiencia, Martin Jay (2009) nos recuerda que existe en lengua alemana dos acepciones del términos: Erlebnis y Erfahrung. La primera, traducida como vivencia, se asocia a una unidad primitiva, previa a cualquier diferenciación y objetivación. Localizada en el mundo cotidiano del lugar común y las prácticas no teorizadas, puede indicar, asimismo, una ruptura con la trama de la rutina cotidiana. La segunda expresión, en cambio, implica una temporalidad más amplia, basada en un proceso de aprendizaje, en la integración de los momentos discretos en un todo narrativo, activando el vínculo con la memoria. Aunque pueden verse variantes e inclusive definiciones en sentido opuesto, la primera estaría indicando la condición inefable del individuo, mientras que la segunda daría cuenta del carácter colectivo de la experiencia.

En esa oscilación entre lo individual y lo colectivo, entre la vivencia y el saber, entre la presencia y el significado, entre el sentido y aquello que se le resiste, las prácticas performativas (entre ellas, por 
supuesto, el teatro) constituyen un territorio de exploración privilegiado, porque representan la experiencia humana justamente como efecto de este movimiento, de esa relación. A continuación, entonces, propongo una aproximación a la escena teatral argentina en que el sabor de lo efímero y la intervención de los significados oscilan como efectos de la experiencia vivida y compartida. Se trata de algunos de los últimos trabajos realizados en Argentina por la escritora, actriz y directora teatral Lola Arias ${ }^{2}$ (1976): Striptease, Sueño con revolver y El amor es un francotirador (trilogía realizada en el Espacio Callejón entre 2007 y 2008); Mucamas (instalación teatral realizada en el Festival Ciudades Paralelas en 2010); y Mi vida después (espectáculo de teatro documental realizado en el Teatro Sarmiento, La Carpintería y el Centro Cultural General San Martín entre 2009 y 2012).

\section{La Presencia de lo Íntimo}

La trilogía puede leerse, según su autora, de dos maneras: como la historia de un personaje (masculino) que va del pasado (Striptease) al futuro (Sueño con revólver) y su sueño (El amor es un francotirador); o como un ensayo del inicio del amor (Sueño con revólver), de su final (Striptease) y de su duelo (El amor es un francotirador).

Sintéticamente, en Sueño con revólver (2007) un hombre y una joven mujer pasan la primera noche juntos, no se conocen, apenas saben sus nombres, están en la casa de él. En una ciudad del futuro sin luz, dividida en barrios alambrados, dos personas conversan en la intimidad, a oscuras, después de hacer el amor. Todo se sucede vertiginosamente en ese primer encuentro: las confesiones, las peleas, los reproches, el sexo, la amenaza de muerte y el amor. En Striptease (2007), la historia de una pareja que se está separando resulta la historia de dos personajes secundarios cuyo protagonista es un bebé, un protagonista mudo e indescifrable, un robot melancólico, según la autora, alrededor del cual el amor ya no está y, sin embargo, no puede tener un final, porque es necesario seguir hablando de él. Finalmente, El amor es un francotirador (2006) se desarrolla en una especie de set de filmación, un dispositivo perfecto, señala la dramaturga, para que un grupo de personas hagan sus confesiones y pidan sus últimos deseos mientras juegan a la ruleta rusa. Se trata de un grupo de corazones rotos que quieren purgar sus penas de amor. Las reglas del juego y el revólver son custodiados por una niña (que, al 
igual que el bebé, es una especie de testigo del juego dramático de los adultos); los jugadores: la stripper, el boxeador, la chica del campo con guitarra, el tímido, la belleza y el Don Juan; los acompaña una banda de rock. La niña finalmente tirará un dado; saldrá un número y alguien morirá; el texto no dice quién y la representación se guiará por las regla del azar (la única prescripción: cualquiera, menos el Don Juan, puede morir).

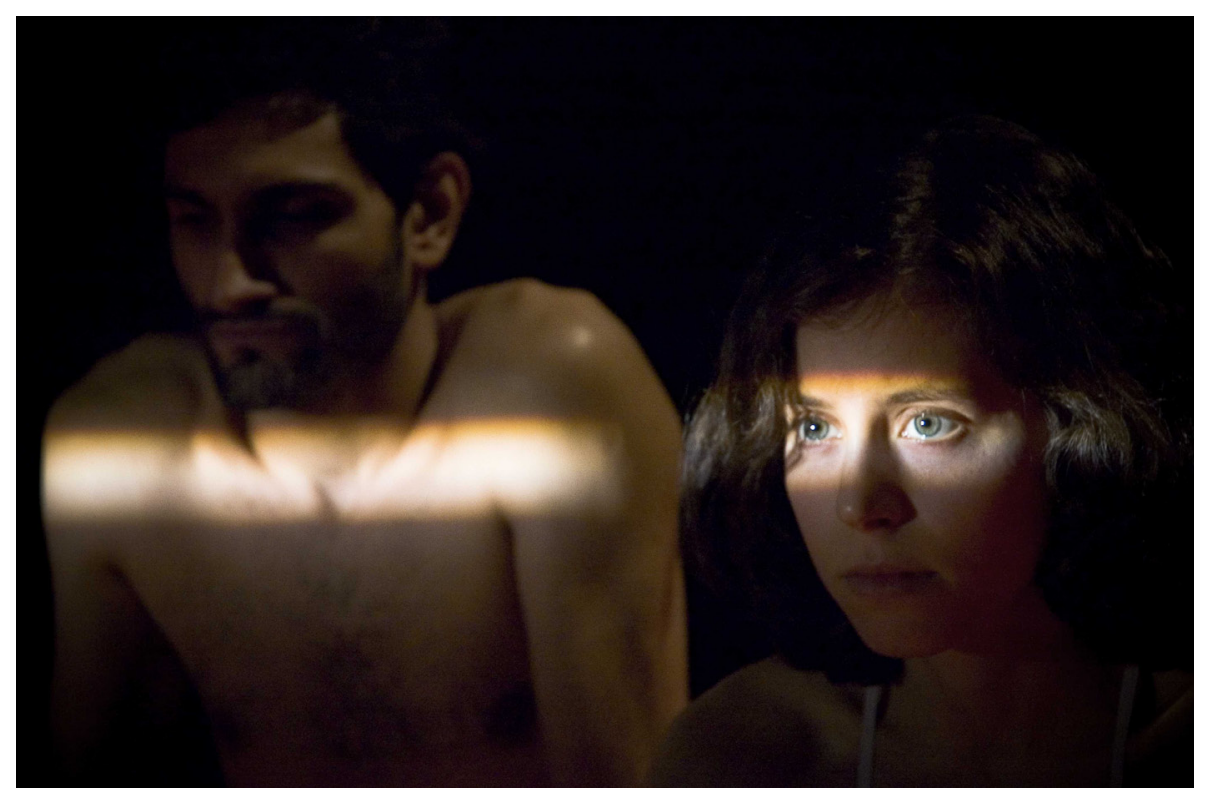

Imagen 1 - Sueño con revólver (Lola Arias, 2007). Fotografía: Lorena Fernández.

Inicialmente escritos por separado, luego reescritos y editados en 2007, los textos se configuran como piezas de un mismo discurso amoroso que sirve, a su vez, para hablar de los resortes que sostienen el hecho escénico y construyen su teatralidad. Así, el apéndice que acompaña la trilogía, a modo de bonus track, se desplaza de la dramaturgia hacia los problemas de la puesta en escena. La música en vivo, la sonoridad de la palabra cantada, la kinestesia del cuerpo que danza, el dispositivo del circuito cerrado de imagen que permite ver el aquí de la escena y el allá de un espacio otro (de la representación de un sueño, de la banda de rock, del disparo final), las propias biografías de los actores como parte de los relatos de ficción (El amor es un francotirador); el casting del bebé (finalmente, una niña), la relación de una madre/actriz con su pequeña hija y la permanente amenaza a la representación (Striptease); la penumbra que atenta contra la visibilidad del espectáculo (Sueño con revólver) son algunas de las cuestiones a resolver en la puesta en escena y en donde los textos 
dejan espacios abiertos, provisorias indicaciones que adquieren toda su expresividad teatral en el aqui y ahora de cada función.

Me interesa introducir dos aspectos del trabajo escénico de la trilogía: primero, la presencia del bebé como un elemento de la realidad que pone en riesgo la ficción y segundo, el desempeño escénico de los actores como contrapartida del trabajo de amor. Encuentro que ambos recursos permiten pensar el modo en que el teatro contemporáneo busca expandir sus fronteras y los regímenes estéticos que separan la ficción de la realidad. Inversamente, también permiten observar el carácter teatral de las conductas humanas en sociedad.

Así, la bebé interviene en el plano de la ficción sin intención de hacerlo y ese grado cero de representación transforma su presencia en un elemento imprevisible tanto para la ficción como para la realidad de cada función, al mismo tiempo que vuelve ostensible los efectos (y los afectos) que su sola presencia despierta en los espectadores ${ }^{3}$. A su vez, la propuesta busca tematizar las convenciones sociales que rigen el vínculo de la madre y la hija, cuestionar su naturalización ${ }^{4}$. De este modo, el bebé nos devuelve no sólo las convenciones que rigen la escena y nuestra relación con ella, sino también las convenciones que regulan nuestros comportamientos culturales.

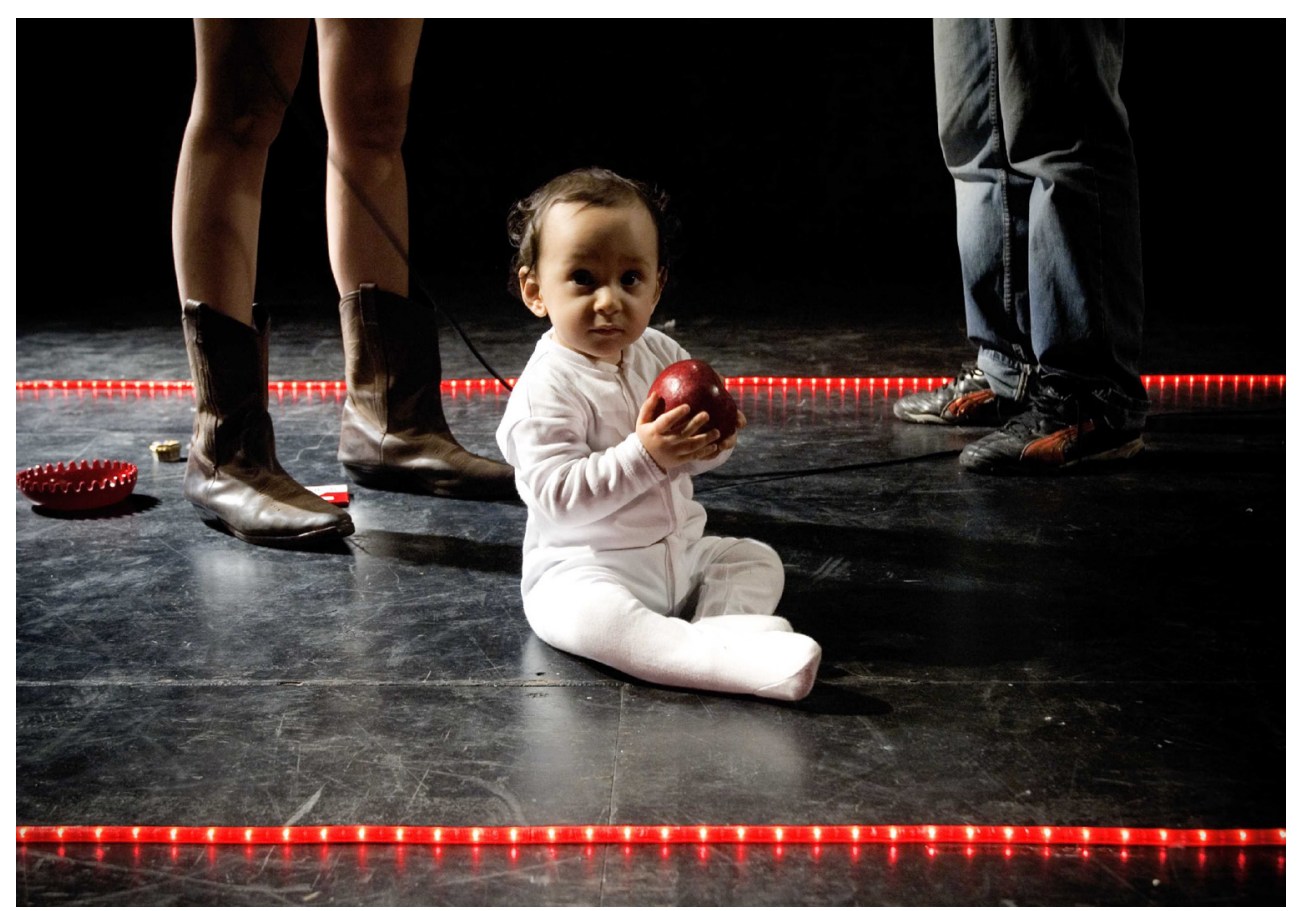

Imagen 2 - Striptease (Lola Arias, 2007). Fotografía: Lorena Fernández. 
En El amor es un francotirador se plantea la interacción humana en términos de destrezas que hay que entrenar y sobre las que hay que aprender fuera y dentro del teatro. Así, se pone en juego lo que la autora considera los aspectos deportivos de la actuación (cuando los actores se besan, se golpean, lloran) y, análogamente, de los sentimientos humanos en general. Como dice el personaje de Don Juan:

A veces pienso que EL AMOR ES ACTUACIÓN. El amor se siente pero sobre todo se actúa. Todos conocemos la comedia del amor: no dormir, no comer, llorar en cualquier lado sin razón aparente, correr desnudo por las autopistas, gritar hasta hacer sangrar las encías, prender fuego cartas, ropa, a todo, pasar las horas en la cama sin moverse intoxicado de amor (Arias, 2007, p. 71-72).

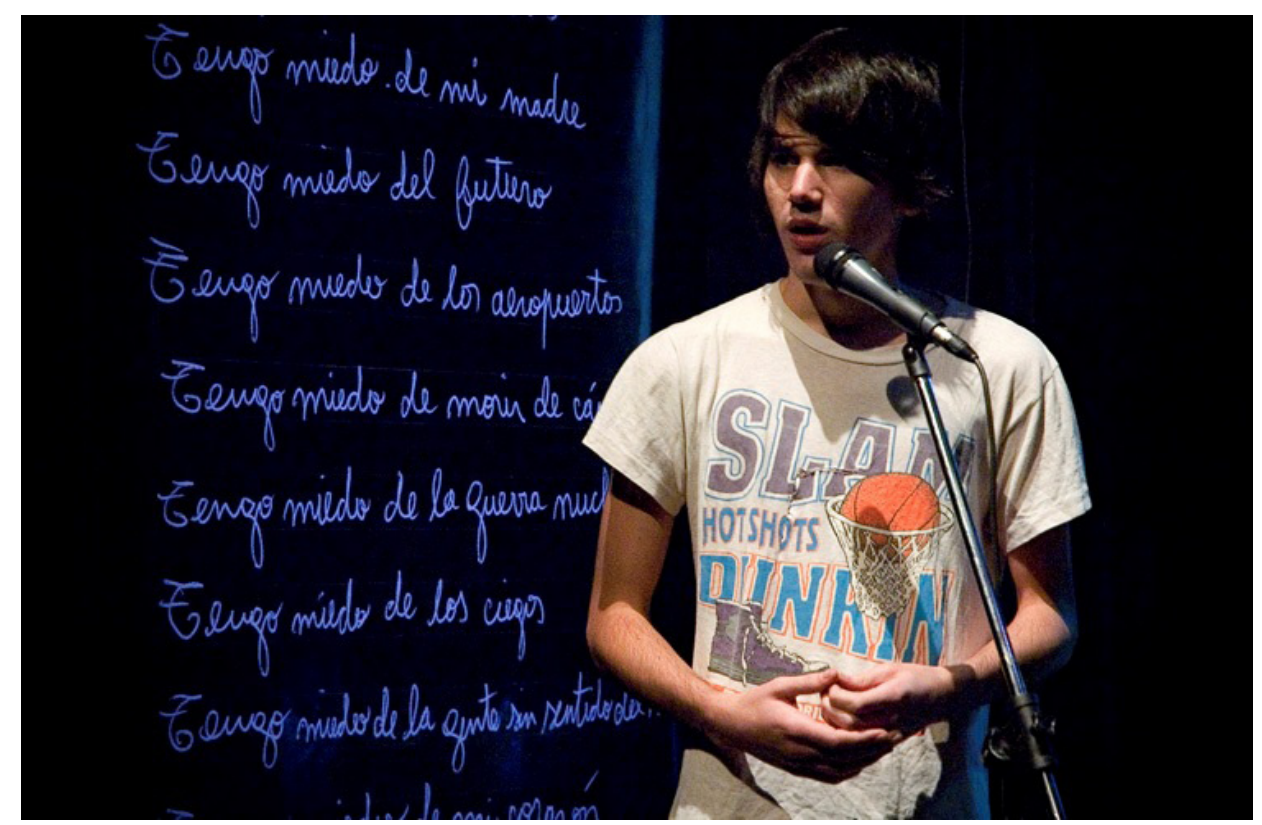

Imagen 3 - El amor es un francotirador (Lola Arias, 2006). Fotografía: Lorena Fernández.

Como señala la directora, aquí la actuación no sólo se lleva a cabo, sino que se parodia, porque todo aparece expuesto como construcción. No se busca una acción orgánica, que conecte eficacia y verosimilitud escénica, o una acción que permita evocar los sentimientos y/o los argumentos de los personajes de ficción como ensayaron los maestros del siglo XX, empezando por Stanislavski (De Marinis, 2005). Se trata, en cambio, de la producción artificial y gratuita de una acción que resulta verdadera no sólo porque efectivamente los actores lloran o se besan, sino porque puede producir una emoción verdadera en el espectador. Si la actuación como acrobacia de los sentimientos remite a la idea artaudiana del actor como 
atleta del corazón y, con ella, una idea respecto de sus técnicas y sus efectos escénicos, las analogías del enamorado, del atleta y del actor recuerdan a los fragmentos del discurso amoroso barthesianos:

Dis-cursus es, originalmente, la acción de correr aquí y allá, son idas y venidas, 'andanzas', 'intrigas'. En su cabeza, el enamorado no cesa en efecto de correr, de emprender nuevas andanzas y de intrigar contra sí mismo. Su discurso no existe jamás sino por arrebatos de lenguaje, que le sobrevienen al capricho de circunstancias ínfimas, aleatorias. Se pueden llamar a estos retazos de discurso figuras. La palabra no debe entenderse en sentido retórico, sino más bien en sentido gimnástico o coreográfico. [...] Así sucede con el enamorado presa de sus figuras: se agita en un deporte un poco loco, se prodiga, como el atleta; articula, como el orador; se ve captado, congelado en un papel, como una estatua. La figura es el enamorado haciendo su trabajo (Barthes, 1982, p. 13-14).

Entre la acción y la palabra, entre la praxis y el discurso, entre la coreografía y la retórica, la escena teatral resulta una caja de resonancia del pensamiento contemporáneo en torno a la condición performativa de la subjetividad y la experiencia. El enamorado se constituye como tal haciendo su trabajo, lo mismo el actor y lo mismo el espectador. $\mathrm{Al}$ igual que el enamorado, el actor se agita un poco loco, articula como el orador, queda congelado como una estatua en el trabajo de la performance. Asimismo, la reposición de los parlamentos y de los objetos de una obra a otra no sólo da cuenta del carácter repetitivo de los rituales del amor y de la propia representación teatral, sino que convoca al espectador a disfrutar de su aparición en un nuevo contexto y así poner en relación el acontecimiento singular con una cadena de significación más extensa.

\section{La Presencia de la Historia}

Ya en El amor es un francotirador, Arias comienza a trabajar con las biografías de sus actores como un modo de incorporar sus experiencias e involucrarlos de modo más personal en el trabajo artístico. En aquel momento comentaba:

Trabajando con actores, cada vez me interesa más la experiencia del actor, no porque siempre vaya a trabajar con su propia vida, sino por incluir determinados elementos que lo coloquen en un lugar de mayor vulnerabilidad, de menos distancia, de más presencia, de más exposición de sí mismo (Pinta, 2008, p. 5). 
$\mathrm{Al}$ año siguiente, estrena Mi vida después (2009), texto y espectáculo cuyo punto de partida es la convocatoria que Vivi Tellas le hace desde el ciclo que dirigía en el Teatro Sarmiento y que sintetizaba del siguiente modo:

Biodrama se inscribe en torno a lo que se podría llamar el 'retorno de lo real' en el campo de la representación. Después de casi dos décadas de simulaciones y simulacros, lo que vuelve -en parte como oposición, en parte como reverso- es la idea de que todavía hay experiencia, y de que el arte debe inventar alguna forma nueva de entrar en relación con ella (Tellas, 2002, p. 2).

Arias propone, entonces, aproximarse al cruce entre la vida privada y la historia argentina reciente desde los relatos de seis actores que, mediante recuerdos (propios y ajenos) y documentos reconstruyen teatralmente la juventud de sus padres marcada por la violencia de la última dictadura militar, la militancia política, el exilio, la desaparición de personas, la apropiación ilegal de bebés, pero también por experiencias de vida alejadas de la participación política. La directora señalaba en el programa del espectáculo: 'Mi vida después' transita por los bordes entre lo real y la ficción, el encuentro entre dos generaciones, la remake como forma de revivir el pasado y modificar el futuro, el cruce entre la historia del pais y la historia privada. Así, mediante la operatoria del remake, se seleccionan fragmentos de la vida cotidiana, anécdotas familiares, recuerdos personales e historias imaginarias que se complementan con cartas, objetos, juguetes, fotos, cintas de audio, ropa, escenas recreadas y/o reproducidas audiovisualmente. Se trata de un volver a hacer de cara al público, una actividad precaria y fragmentaria que se desarrolla en un horizonte postproductivo (Bourriaud, 2007) en el que la edición y yuxtaposición de elementos heterogéneos configuran nuevos objetos estéticos y nuevas cadenas de significación.

Los objetos testimoniales cobran una particular relevancia, ya que se presentan como indicios, como huellas de lo que está ausente y se pretende hacer presente mediante la escenificación. En una escena, uno de los actores escucha, junto a su propio hijo, la voz del padre/ abuelo a través de una cinta magnetofónica. La cinta nos devuelve la dimensión sonora de la voz del padre, revela un haber estado allí, una indicialidad. El mismo funcionamiento se establece con la exhibición de los materiales fotográficos y los objetos, ambos tendientes a fortalecer esta constante presencia de operatorias indiciarias. El 
objeto escénico que presenta este rasgo indicial paradigmático es la ropa; los actores se disfrazan (como los niños) y ese juego les da una identidad narrativa múltiple: la de ellos mismos, las de sus padres y las de otros personajes. En definitiva, aquello que sólo era un objeto deviene luego, gracias al relato y la puesta en escena, un instrumento de conocimiento y experimentación del pasado y un modo de producir subjetividad.

Así, el relato se construye a partir de la memoria y el deseo (con respecto al pasado pero también al futuro) propio y ajeno en dos niveles: por un lado, la memoria/deseo de los hijos; por otro lado, la memoria/deseo de la autora/directora que, a partir de los relatos de los hijos/actores construye su propio relato. De este modo, el relato se configura como mirada y voz de un yo (de los actores y de la directora) que construye su propio relato a partir del relato de otros yo que le permiten pensar su propia condición (histórica) en el mundo. Y esta apelación del yo a partir de las biografías de sus vínculos cercanos no hace otra cosa que poner en el centro de la escena (teatral, pero también cultural) la configuración intersubjetiva del yo como intersección de múltiples subjetividades.

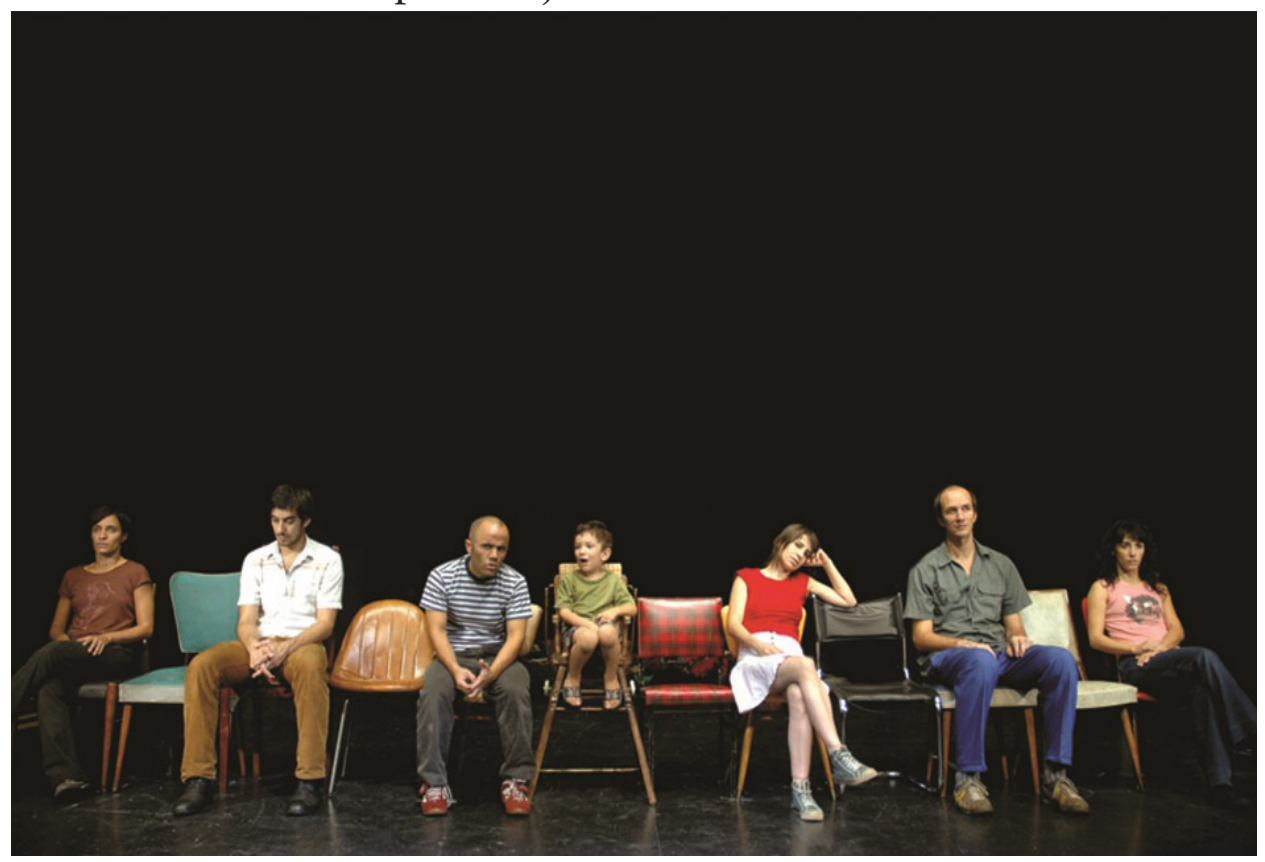

Imagen 4 - Mi vida después (Lola Arias, 2009). Fotografía: Lorena Fernández.

Ahora bien, así como Mi vida después tematiza ampliamente la presencia del pasado en la actualidad y busca explorar las estrategias poéticas y afectivas con las que reconstruir la historia individual y colectiva, también se pregunta por el futuro de sus protagonistas, 
quienes exponen, sobre el final del espectáculo, sus sueños y fantasías. Pero la reposición del espectáculo a lo largo de cuatro años consecutivos lo ha ido modificando en sintonía con el desarrollo de la vida de sus actores y el futuro, finalmente, se filtra como el presente de su última presentación de 2012. De este modo, Carla Crespo, que en el momento del estreno esperaba los resultados de un estudio de ADN para conocer el destino de los restos mortales de su padre (integrante del Ejército Revolucionario del Pueblo), luego sabrá que se encontraban en una fosa común (donde se entierran varios cuerpos sin identificación) de Avellaneda; a ello se suma la llegada de su primer hijo junto a su compañero de elenco, Pablo Lugones. Vanina Falco, hija de un policía que se apropió ilegalmente de un bebé nacido en el Centro Clandestino de Detención, Tortura y Exterminio que funcionaba en la Escuela de Mecánica de la Armada (ESMA), finalmente logrará declarar en contra de su padre, actualmente detenido. Estos son sólo algunos ejemplos de los cambios introducidos en la trama de Mi vida después y representan la dinámica de un teatro que se nutre de una historia vivas.

Se trata también de una historia narrada en vivo, en primera persona y en cuerpo presente. Y este aquí y ahora propio de la representación teatral tiene un lugar central en los momentos conmovedores en los que los hijos buscan reconstruir una historia dolorosa, llena de ausencias, interpelando al espectador desde el humor pero también desde una voz que no es la víctima directa de la violencia, aunque sí su heredera. La tarea, entonces, será la del arqueólogo; deberá exhumar objetos, hacer hipótesis, imaginar y representar escenas. La experiencia del actor en escena, entonces, será la del trabajo de exponer, narrar, actuar, cantar, bailar, manipular los dispositivos tecnológicos y, a la vez, la de exhibir su propia historia íntima y personal; el resultado, como señalaba Arias anteriormente, es de una gran exposición de sí mismo y, con ello, de vulnerabilidad.

\section{La Presencia de lo Biográfico}

El Festival Ciudades Paralelas ${ }^{6}$ (Buenos Aires, 2010) explora los distintos usos teatrales de una gran ciudad. El objetivo del ciclo es indagar sobre los diferentes dispositivos escénicos de la experiencia de la ciudad presentes en lugares públicos, privados, espacios de consumo, de trabajo, de transporte, de ocio, etcétera, para observar su funcionamiento desde otro lugar. Así, ocho artistas trabajan so- 
bre ocho lugares de la ciudad para crear observatorios de situaciones urbanas. Algunos de ellos intervienen el espacio con una emisión de radio o con un coro; otros invitan a espiar lugares desde afuera o a recorrerlos con sus trabajadores. Se apela a distintos formatos artísticos y a diferentes modos de aprehensión de la obra de arte (escuchar, leer, tocar, caminar, mirar). También varía la cantidad de participantes, desde una única persona a un grupo numeroso. Los performers pueden ser cantantes, escritores, actores no profesionales, pero también los propios espectadores, cuando no los paseantes ocasionales. El festival fue programado para desarrollarse en distintas ciudades del mundo (Berlín y Buenos Aires, 2010; Varsovia y Zúrich, 2011 y continúa). En cada edición los espectáculos deben rehacerse a partir de las nuevas circunstancias que el entorno urbano proporciona.

En su doble rol de curadora (junto a Stefan Kaegi) ${ }^{7}$ y directora teatral, Lola Arias presenta en esta oportunidad la instalación $\mathrm{Muca}$ mas donde investiga, en clave documental, los relatos biográficos del personal de limpieza de las grandes cadenas de hoteles (en esta oportunidad, mujeres inmigrantes de distintas partes de Argentina). El proyecto apunta a visibilizar las historias de vida de aquellas personas que suelen estar ausentes en la experiencia del huésped, aunque entran en contacto con él a partir de las huellas de sus prácticas y objetos íntimos. El espectador tiene la oportunidad de recorrer un conjunto de habitaciones en un tiempo pautado (los diez minutos que demora la limpieza de cada habitación) y conocer en ellas los distintos relatos de vida del personal del hotel (en este caso, se trató del Hotel Ibis). Cada habitación se configura como una instalación con objetos, imágenes fotográficas, sonidos y vídeos que documentan y testimonian las narraciones biográficas (desengaños amorosos, cumpleaños, mudanzas, casamientos, anécdotas de trabajo, entre otros acontecimientos). Al final del recorrido el espectador se encuentra con una de las mucamas con quien podrá dialogar mientras caminan por la trastienda del hotel hasta la despedida final. El itinerario del espectador comienza con su ingreso por la puerta principal (de los huéspedes), continúa con el recorrido por las habitaciones desocupadas aunque llenas de objetos ajenos y termina con su egreso por la puerta de servicio (de los trabajadores). Aquí, nuevamente, el recorrido ilumina momentos en los que lo colectivo y lo personal se encuentran en las migraciones, el desarraigo, los vínculos familiares, las experiencias laborales y el anonimato de la vida cotidiana en la ciudad. 


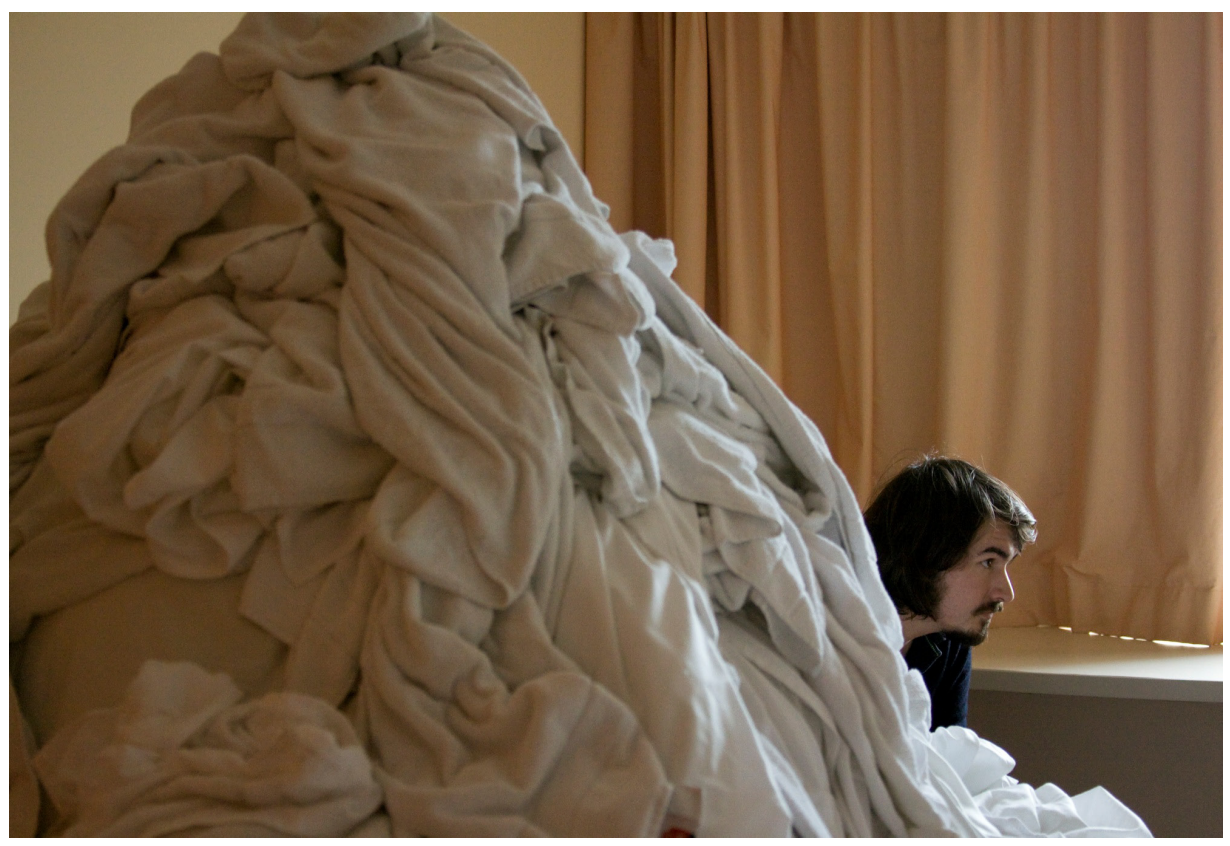

Imagen 5 - Mucamas (Lola Arias, 2010). Fotografía: Lorena Fernández.

Esta tematización de la vida en la ciudad presenta una larga tradición en la historia del arte que ha ensayado diferentes figuraciones de la gran metrópolis en clave de promesa y/o decepción de los procesos de masificación y globalización. En este contexto, el teatro se vislumbra como espacio de reflexión crítica frente a la ciudad espectacularizada. Lola Arias señala al respecto:

La ciudad es un teatro vivo. [...] Observar los gestos, comportamientos y estados en lo que nos sumergimos al entrar en determinados espacios todos los días es pensar sobre la teatralidad de la ciudad, sobre lo que hace la arquitectura con nuestros cuerpos, sobre los mecanismos de control, sobre la manera en que miramos y actuamos cada vez que ponemos los pies en el suelo de nuestra ciudad (Pitrola, 2010-2011, p. 62).

Resulta, como podemos seguir de las palabras de la artista, que la ciudad con sus usos, prácticas y consumos cotidianos también ofrece modelos de comportamiento y, sobre todo, estrategias para pensar la actividad teatral y el campo artístico en su conjunto. Efectivamente, la producción artística de las últimas décadas encuentra en los modos de conversación cotidiana, en las maneras de habitar la ciudad, en los vínculos interpersonales, en los relatos autobiográficos, en las actividades domésticas y, sobre todo, en las personas anónimas y no profesionales que protagonizan esas experiencias vitales y colectivas, un material estético inédito con el que revitalizar aquel tópico arte- 
vida que recorre las vanguardias artísticas del siglo pasado. Como señala Reinaldo Laddaga (2006):

Puede decirse que de sus operaciones resulte ni una obra de arte concluida ni la cancelación de su posibilidad. $\mathrm{Ni}$ la afirmación de una distancia del arte respecto de la vida ni su simple anulación. En estos proyectos se construyen transiciones: entre el espacio de las galerías y los museos y el lugar donde tienen lugar esas operaciones entre expertos y no expertos que produce manipulaciones de imágenes o símbolos y modificaciones directas en las relaciones entre los cuerpos. Pero la condición para que estas transiciones puedan extenderse es la pérdida de poder de una presuposición: la de que una práctica sólo puede desplegarse a partir de la demarcación disciplinaria (Laddaga, 2006, p. 263).

En esta mirada del arte a las prácticas cotidianas, el trabajo de Michel De Certeau (2007) se vuelve una referencia insoslayable. Focalizando en las producciones calificadas como consumo, el autor busca reorientar las perspectivas mecanicistas en las que la relación producción/consumo se traducen en los términos de actividad/pasividad y con ellos en los de una manipulación de los primeros sobre los segundos. Por el contrario, el consumo es analizado en términos de una producción poiética, de diversas maneras de hacer en tanto arte. Se trata de una producción astuta, silenciosa y dispersa, pero que se insinúa en todas partes y es casi invisible, tácticas que no se señalan con productos propios, sino en las maneras de emplear los productos impuestos por el orden económico dominante. Se trata de prácticas cotidianas contrarias a las formas racionalizadas, expansionistas, centralizadas, ruidosas y espectaculares. En este sentido, el Festival Ciudades Paralelas se proponen como una práctica que interpela a los espectadores acerca de los modos de frecuentar un lugar, de desviarse de los caminos prefigurados por la planificación urbana, de trazar topologías personales atravesadas por el recuerdo, las experiencias y el deseo. Trata también de los relatos acerca del espacio y, sobre todo, de aquellos recorridos o itinerarios cuya exacerbación del hacer y del sentir se instauran como los modos de reapropiarse de un orden (urbano) impuesto.

Ladagga también señalaba que la condición para que estos intercambios y transiciones entre los espacio del arte y la vida, entre expertos y no expertos, es la suspensión de la idea de los campos disciplinares y de su especificidad. En ocasión de la trilogía ${ }^{8}$, Lola Arias hacía referencia a su interés personal en este tipo de trabajo y aquí lo reafirma: 
Creemos en un teatro fronterizo entre la música, la literatura, la radio, las artes visuales. En general el teatro aplasta todas las artes que lo integran al servicio de la idea del director [...]. A nosotros nos interesa el teatro que piensan los artistas que no vienen del teatro, porque inventan procedimientos inéditos (Pitrola, 2010-2011, p. 61).

Este cruce de prácticas estéticas artísticas y no artísticas, análogo a los intercambios anteriormente mencionados entre el teatro y las performance culturales, puede ser abordado también desde la teoría de la traducción. Según Nicolas Bourriaud (2009, p. 162-165), la traducción, en tanto práctica de desplazamiento, realza el paso de los signos de un formato a otro, transfiere elementos de una cultura a otra donde se ven puestos en movimiento y quedan al alcance de una lectura crítica. En Ciudades Paralelas esta operación de traducción se presenta en, al menos, tres niveles: pasaje de una disciplina a artística a otra, desplazamiento de una esfera de la vida social a otra (entre las prácticas artísticas y la vida cotidiana) y, finalmente, de un contexto geopolítico a otro (entre centros y periferias). Para Bourriaud, la traducción se presenta, a su vez, como una forma ética de reconocimiento del otro que, a partir de los códigos y referencias propios, hace entrar su singularidad en resonancia con la historia ajena. Esta perspectiva coincide en parte con la teoría de la traducción de Jacques Rancière (2010) para quien tanto el espectador como el artista deberán desplegar sus competencias y observar los intercambios en una escena, cuyos resultados son inciertos y dependerán de un espectador emancipado capaz de apropiarse de la historia para transformarla en su propia historia. Algo de ello se persigue también en Ciudades Paralelas, no sólo cuando los artistas deben montar sus propuestas en diferentes contextos urbanos y trabajar con lo que el medio les ofrece, sino también en los intercambios que los espectadores de una ciudad pueden experimentar con las historias de vida y recorridos que las piezas les proponen.

Itinerarios y traducciones mediante, Ciudades Paralelas conecta escenarios locales y globales. Estos emergen no sólo en las experiencias entre las diferentes ciudades, sino que surge también en los recorridos aleatorios, los usos subvertidos y los encuentros imprevistos dentro de una misma ciudad. De la biblioteca al shopping, del palacio de justicia a la fábrica, del hotel a la estación de tren, del edificio de departamentos a la terraza, lo local y lo global así como la metrópolis y sus 
periferias quedan representadas en las trayectorias, las experiencias y los relatos de vida que ofrecen las performances.

Entre el régimen posproductivo (en tanto trabajo de interpretación y reutilización de todo tipo de productos culturales disponibles) y la estética relacional (que concibe la realización artística como un terreno propicio para la experimentación de nuevos modelos de sociabilidad); o sea, entre el reciclaje cultural y la exploración de los vínculos intersubjetivos (Bourriaud, 2007; 2008), la teatralidad de Ciudades Paralelas enlaza con las tácticas de la vida cotidiana y su esteticidad. En este horizonte, entonces, el proyecto ensaya un modo de pensar la experiencia histórica de su propio tiempo a partir de los escenarios y los personajes de las ciudades contemporáneas.

\section{A Modo de Conclusión. La Presencia del Cuerpo en la Cultura Contemporánea}

Para finalizar este artículo quisiera sumar dos enfoques políticos y éticos en torno a las experiencias teatrales analizadas. La primera de estas reflexiones se encuentra desarrollada por Claire Bishop (2010-2011), quien observa cierto giro social de las prácticas artísticas contemporáneas caracterizado, ya desde los ańos noventa del siglo pasado, por la presencia de distintas modalidades de subcontratación de personas profesionales o no profesionales para que realicen distintas tareas en nombre del artista. Dos de estas modalidades se pueden observar a partir de los trabajos de Lola Arias. Por un lado, la contratación de no profesionales (del arte) para que actúen sus propias identidades (en los casos de Mucamas y en el del bebé de Striptease). En el primer ejemplo, la tematización del trabajo de las empleadas de limpieza del hotel en tanto personajes anónimos, trabajo invisibilizado y poco remunerado, dirige la atención hacia los sistemas económicos y la lógica del mercado laboral, pero también hacia las historias de vida y de sus universos afectivos. En el ejemplo del bebé, la experiencia se propone como pura empatía y afectividad, pero, a la vez, como una instancia desestabilizadora de las categorías estéticas de la representación.

Por otro lado, la contratación de otros artistas. Aquí habría que decir que el teatro se ha valido largamente de la colaboración de distintas disciplinas (músicos, arquitectos, artistas visuales, coreógrafos etc.); y que esa característica no sólo constituye su especificidad estética, sino que ha servido como modelo de los distintos progra- 
mas interdisciplinarios que se han sucedido desde el siglo XIX a la actualidad. En el caso de Mi vida después, esta modalidad se complejiza porque, si bien los actores son profesionales, su convocatoria respondía también a sus historias personales. Tanto en el caso de $E l$ amor es un francotirador como en el Festival Ciudades Paralelas, Lola Arias en su rol de directora y curadora respectivamente, se interesa por hacer explícita la convocatoria a artistas de distintas disciplinas como elemento fundamental de los proyectos. En ambos casos, sus participaciones incluyen ciertas pautas y/o estructura proporcionadas por la artista pero también cierto margen de intervención artística y personal. A su vez, algunas colaboraciones se dan en el plano de la realización del espectáculo (fuera de escena) y otras se dan como performers (dentro de la escena); éstas últimas resultan más próximas a la modalidad analizada por Bishop.

Entre una y otra categoría, la autora señala un elemento de intercambio económico propio de las sociedades contemporáneas y, por extensión, inscripto también en el campo de los bienes simbólicos: el cuerpo como principal y única forma válida de moneda. Siguiendo a Pierre Klossowki y a Pierre Bal-Blanc ${ }^{9}$, la autora indica que la distinción del uso y el no uso, de lo funcional y lo no funcional, de los procesos industriales y del arte, queda superada en la medida que se comprende que ambos participan del carácter a la vez libidinal y racional de los sistemas económicos existentes. Concebido como moneda viviente, el cuerpo se ve atravesado por el placer del participante que explota su subordinación y por el placer del espectador que lo observa; y esta dinámica resulta fundamental para comprender la relación entre el arte contemporáneo y la mercantilización de lo corporal. La autora encuentra que el valor de muchas performance delegadas estaría justamente en reescenificar la tensión dialéctica entre la estructura y la agencia (proceso de subjetivación), lo particular y lo universal, lo espontáneo y lo guionado, el observador y el observado:

Es verdad que en sus peores versiones la performance delegada produce una reificación demasiado simplista: una realidad escenificada de manera caprichosa para los medios, en lugar de una presencia mediada paradójicamente. En sus mejores momentos, sin embargo, genera eventos disruptivos que dan testimonio de una realidad compartida entre espectadores y performers; eventos que desafían no sólo las formas convencionales de pensar la subjetividad, la ética y la economía, sino también los marcos intelectuales que hemos heredado para entender esas ideas hoy en día (Bishop, 2010-2011, p. 72). 
Resulta que el cuerpo no es sólo una moneda viviente, sino también un archivo viviente atravesado por las primeras impresiones de su infancia, por las actividades cotidianas del trabajo, por las experiencias afectivas y por el cruce con la historia colectiva. Como pudimos ver en los ejemplos analizados, no se trata sólo de la simple exhibición de destrezas y/o características particulares; sino que el cuerpo, en tanto archivo, dice más (y menos) de lo que puede decir. Será el modo en que hilvane recuerdos propios y ajenos, disponga sus objetos, recuerde a sus muertos, imagine su futuro, ensaye historias de amor, llore sus duelos, nos devuelva la mirada en silencio; en definitiva, ponga su humanidad en escena, aquello que finalmente nos interpelará en tanto espectadores.

Se suma, de este modo, una segunda perspectiva que pone el foco en la fusión poético-política de ciertas prácticas artísticas que privilegian las operaciones del archivo y considera la articulación entre una macro y una micropolítica. Según Suely Rolnik (2010), mientras que la macropolítica se estructura en torno a los grandes relatos, personajes y retóricas de la historia, la micropolítica no se constituye únicamente por su referencia a temas explícitamente políticos, sino por proponer cierto tipo de organización poética y de experiencia del espectador. En palabras de la autora:

No se trata de la conciencia de la dominación y de la explotación (su cara extensiva, representativa, macropolítica), sino de la experiencia de este estado de cosas en el propio cuerpo (su cara intensiva, inconsciente, micropolítica). Esta experiencia puede intervenir en el proceso de subjetivación precisamente en el punto donde éste tiende a permanecer cautivo y a despotencializarse (Rolnik, 2010, p. 122-123).

En tiempos en los que la hipermediatización de la experiencia parecería ser el signo de época más característico; las prácticas performativas y sus efectos de presencia representarían algunas de las posibles estrategias políticas del arte contemporáneo. Así, en los límites de la representación teatral, entre el archivo (a la vez histórico y personal) y la experiencia (a la vez sensible, corporal e intersubjetiva), un conjunto significativo de proyectos artísticos buscan articular poética y políticamente una práctica y un conocimiento del mundo actual. Y en esta línea pueden identificarse los trabajos de Lola Arias aquí estudiados. 


\section{Notas}

${ }^{1}$ Pavis se refiere a: Traditional India: Structure and change (Singer, 1959).

${ }^{2}$ Disponible en: <http://www.lolaarias.com.ar/>.

${ }^{3}$ Lola Arias señalaba: "En la puesta en escena me interesó ir más lejos en relación a lo real; es decir, poner en riesgo la ficción. La obra del bebé es la más radical en ese sentido. Estoy atentando contra mi propio texto, porque el bebé puede llorar toda la función y no hay texto; es como tomar un riesgo real extremo, porque me interesa algo más que la enunciación del texto, que es la experiencia en sí; es decir, como espectadora, cuando estoy viendo un bebé en escena, me pasan un montón de cosas que tiene que ver con lo que está fuera de control, lo que es real, lo que es puro acontecimiento que da otro tipo de emoción y de predisposición" (Pinta, 2008, p. 5-6).

${ }^{4}$ Lola Arias comentaba: "Me interesa la relación de los padres y los hijos. Son sentimientos que también se tienen, el bebé está llorando y decís "lo voy a tirar por el balcón”, pero es algo que se dice y no tiene nada que ver con el amor. Hay momentos de locura, de querer estar sola y todo el mundo niega eso. Hay muchos matices en esa relación y ahí lo ves en una relación real, con un bebé de plástico se vuelve pura teoría. Lo más fuerte es que ellas están ahí. Eso no quiere decir que no lo ame, simplemente es alguien que se pregunta por ese vínculo" (Pinta, 2008, p. 8).

${ }^{5}$ Blanc (2012). Entre el 27 y 28 de octubre de 2012 se presentó en el Teatro Sarmiento de Buenos Aires El año en que nací, versión chilena que Lola Arias realiza luego de un taller llevado a cabo en Santiago de Chile con motivo de la exhibición de Mi vida después en el Festival Santiago a Mil de 2011.

${ }^{6}$ Ciudades Paralelas se realizó en Buenos Aires desde el 26 de noviembre hasta el 5 de diciembre de 2010. Disponible en: <http://www.ciudadesparalelas.com/>.

${ }^{7}$ En Chacara paraíso (2007) y Airport Kids (2008), espectáculos no estrenados en Argentina, Arias trabaja junto a Kaegi la relación documental/ficción explorando la vida de policías y familiares de policías en Brasil (el primero), así como la vida de niños de múltiples nacionalidades y lenguas que se encuentran en permanente tránsito por los aeropuertos del mundo (el segundo). Disponible en: <http://www.lolaarias.com.ar/>.

${ }^{8}$ Lola Arias indicaba: "La Compañía Posnuclear es un colectivo de artistas de distintas disciplinas, un músico, un cineasta, un artista visual, una coreógrafa y yo. La idea de tener cinco artistas de mi generación que producen tiene que ver con dejar que las otras artes tomen también su espacio en la performance. La música es independiente y tiene tanto valor como el texto, como la coreografía, como la imagen. Es un interés por una mayor contaminación de las artes, de mayor fricción, de menos predominio del relato. La tercera obra es una obra musical prácticamente. Me interesa buscar más en el borde del teatro. El trabajo con lo real y la incomodidad del espectador tiene que ver también con una invasión de territorios" (Pinta, 2008, p. 9).

${ }^{9}$ Bishop se refiere a: Sade mi prójimo, precedido de "El filósofo malvado"(Klossowski, 1970); La moneda viviente (Klossowski, 1998); Note de mise en scéne: La Monnaie Vivante (Bal-Blanc, s/d). Disponible en: <http://www.cacbretigny.com/inhalt/LAMONNAIEVIVANTE. html>. 


\section{Referencias}

ARIAS, Lola. Trilogía. Striptease, Sueño con revólver, El amor es un francotirador. Buenos Aires: Entropía, 2007.

BARTHES, Roland. Fragmentos de un Discurso Amoroso. Buenos Aires: Siglo XXI, 1982 [1977].

BISHOP, Claire. Performance delegada: subcontratar la autenticidad. Otra Parte - Revista de Letras y Artes, Asociación Civil Otra Parte para las Artes y las Letras, n. 22, p. 63-72, verano 2010-2011.

BLANC, Natalia. La despedida de una obra con constantes variaciones. La Nación Suplemento ADN Cultura, Buenos Aires, 05 oct. 2012. Disponible en: <http://www. lanacion.com.ar/1514090-la-despedida-de-una-obra-con-constantes-variaciones $>$. Acceso en: 09 dic. 2012.

BOURRIAUD, Nicolás. Postproducción. Buenos Aires: Adriana Hidalgo, 2007.

BOURRIAUD, Nicolás. Estética Relacional. Buenos Aires: Adriana Hidalgo, 2008.

BOURRIAUD, Nicolás. Radicante. Buenos Aires: Adriana Hidalgo, 2009.

DE CERTEAU, Michel. La Invención de lo Cotidiano. México: Universidad Iberoamericana/Instituto Tecnológico y de Estudios Superiores de Occidente, 2007.

DE MARINIS, Marco. A través del espejo: el teatro y lo cotidiano. In: DE MARINIS, Marco. Lineamientos de una Nueva Teatrología. Comprender el teatro I. Buenos Aires: Galerna, 1997. P. 171-186.

DE MARINIS, Marco. En Busca del Actor y del Espectador. Comprender el teatro II. Buenos Aires: Galerna, 2005.

ICLE, Gilberto. Estudios de la Presencia: del trabajo del actor a la investigación no interpretativa. Telondefondo - Revista de Teoría y Crítica Teatral, Buenos Aires, Universidad de Buenos Aires, a. VIII, n. 16, p.189-204, dic. 2012. Disponible en: <http://www. telondefondo.org>. Acceso en: 04 dic. 2012.

JAY, Martín. Cantos de Experiencia: variaciones modernas sobre un tema universal. Buenos Aires: Paidós, 2009.

LADDAGA, Reinaldo. Estética de la Emergencia. Buenos Aires: Adriana Hidalgo, 2006.

PAVIS, Patrice. Diccionario de Teatro. Dramaturgia, estética, semiología. Barcelona: Paidós, 1998.

PAVIS, Patrice. Puesta en escena, performance: ¿cuál es la diferencia? Telondefondo - Revista de Teoría y Crítica Teatral, Buenos Aires, Universidad de Buenos Aires, a. IV, n. 7, p. 1-37, jul. 2008. Disponible en: <http://www.telondefondo.org>. Acceso en: 06 jul. 2008.

PINTA, María Fernanda. Escenas de un discurso amoroso I. Entrevista a Lola Arias. Telondefondo - Revista de Teoría y Crítica Teatral, Buenos Aires, Universidad de Buenos Aires, a. IV, n. 7, p. 1-12, jul. 2008. Disponible en: <http://www.telondefondo.org>. Acceso en: 06 jul. 2018. 
PINTA, María Fernanda; BAEZA, Federico. Artes de lo íntimo. In: CORNAGO, Oscar (Org.). A veces me pregunto por qué sigo bailando. Prácticas de la intimidad. Madrid: Continta Me Tienes, 2011. P. 204-235.

PITROLA, Marcelo. Lola Arias y Stefan Kaegi. La ciudad: usos teatrales. Otra Parte Revista de Letras y Artes, Buenos Aires, Asociación Civil Otra Parte para las Artes y las Letras, n. 22, p. 57-62, verano 2010-2011.

RANCIÉRE, Jacques. El Espectador Emancipado. Buenos Aires: Manantial, 2010.

ROLNIK, Suely. Furor de archivo. Estudios Visuales, Murcia, Centro de Documentación y Estudios Avanzados de Arte Contemporáneo, n. 7, p. 116-129, ene. 2007. Disponible en: <http://estudiosvisuales.net/revista/pdf/num7/08_rolnik.pdf>. Acceso en: 20 sep. 2012.

TELLAS, Vivi. Biodrama: descripción del proyecto. Comienza el Ciclo "Biodrama", Buenos Aires, Complejo Teatral de Buenos Aires, n. 30, p. 1-2, 09 abr. 2002.

María Fernanda Pinta es doctora en Historia y Teoría de las Artes (Universidad de Buenos Aires). Docente e investigadora (Departamento de Artes e Instituto de Teoría e Historia del Arte Julio Payró - Universidad de Buenos Aires). Becaria Posdoctoral (Consejo Nacional de Investigaciones Científicas y Técnicas - CONICET). Secretaria de telondefondo. Revista de Teoría y Crítica Teatral (www.telondefondo.org). Miembro del Consejo Directivo de la Asociación Argentina de Investigación y Crítica Teatral (AINCRIT). Publica trabajos sobre temas de artes escénicas. Participa en actividades académicas nacionales e internacionales.

E-mail: fernandapinta@hotmail.com

Recibido el 23 de abril de 2013 Aceptado para publicación el 03 de julio de 2013 